\title{
Leilões para conversão de dívida em investimento: uma proposta da teoria de leilões para implantação dos termos de ajuste de conduta (TAC) da Anatel
}

\author{
Maurício Soares Bugarin \\ Universidade de Brasilia (UnB), Brasília, DF, Brasil \\ Hélio Maurício Miranda da Fonseca \\ Agência Nacional de Telecomunicações (ANATEL), Brasília, DF, Brasil
}

\section{Resumo}

Desde a privatização da Telebrás em 1998, o Brasil tem assistido a uma impressionante expansão nas telecomunicações. Paralelamente, cresceram assustadoramente as dívidas das operadoras de telecomunicação, com elevadas multas regulatórias. Em 2012, a Anatel aprovou a celebração de termos de ajustamento de conduta (TAC) para a conversão de dívida das operadoras em projetos de investimento. A questão crucial é como determinar a taxa de conversão. Este trabalho propõe um mecanismo de leilão para a determinação endógena dessa taxa. Nesse leilão as operadoras propõem taxas de conversão de dívida em um certo investimento, e a operadora que oferecer a taxa mais baixa (menos reais de dívida deduzidos para cada real investido) vence o leilão. Ademais, discute-se como a estrutura sequencial do problema permite desenhar um mecanismo inédito de leilões sequenciais que tem a característica de criar assimetria entre os jogadores, gerando maior bem-estar social e garantindo a implementação dos projetos selecionados.

Palavras-chave: telecomunicações, TAC, leilões sequenciais 


\section{Subastas de conversión de deuda en inversión: una propuesta de teoría de subastas para la implementación de los términos de ajuste de conducta (TAC) de Anatel/Brasil}

Resumen: Desde la privatización del sistema Telebrás en 1998, Brasil ha experimentado una expansión impresionante en las telecomunicaciones. Paralelamente, las deudas de los operadores de telecomunicaciones han crecido enormemente, con multas regulatorias crecientes. En 2012, Anatel aprobó la posibilidad de acuerdos para convertir deuda en proyectos de inversión. La pregunta crucial es cómo determinar la tasa de conversión de deuda a inversión. Este trabajo propone un mecanismo de subasta para la determinación endógena de la tasa de conversión. En esta subasta, los operadores ofrecen tasas de conversión de deuda para una determinada inversión, y vence el operador con la tasa más baja. Además, analiza cómo la estructura secuencial del problema permite la construcción de un mecanismo innovador de dos subastas secuenciales que tiene la característica de crear asimetría entre los jugadores, generando mayor bienestar social y asegurar la implementación de proyectos seleccionados.

Palabras clave: telecomunicaciones, acuerdo de ajuste de conducta, subastas secuenciales

\section{Debt to investment conversion auctions: an auction theory proposal for implementing} Brazilian Anatel's terms of conduct adjustment (TAC)

Since the privatization of Telebrás system in 1998, Brazil has undergone an impressive expansion in telecommunications. At the same time, the debts of telecommunication companies have skyrocketed, with increasingly high regulatory fines. In 2012, Anatel allowed for operators to enter into "TAC" agreements to convert debt into investment projects. The crucial question is how to determine the debt-to-investment conversion rate. This paper proposes an auction mechanism for endogenously setting the optimal conversion rate. In that auction, operators bid debt conversion rates for a certain investment, and the lowest rate bidder wins the auction. In addition, it discusses how the sequential structure of the problem allows for a new mechanism of two sequential auctions that creates asymmetry among the players, thereby generating greater social welfare and ensure the implementation of selected projects.

Keywords: telecommunications, agreement of adjustment of conduct, sequential auctions 


\section{Introdução}

A prestação de serviços de telecomunicações evoluiu de forma intensa no Brasil, sobretudo após o processo de privatização das empresas do sistema Telebrás na década de $1990^{1}$.

Todavia, passados os primeiros anos de intenso esforço dos prestadores de serviços de telecomunicações em atender às metas de universalização, os níveis obtidos de qualidade da prestação dos serviços e de conformidade com as normas geraram grande número de reclamações, levando a um crescimento exponencial do volume de sanções. Essas sanções, por sua vez, resultaram, em seguida, em aumento expressivo do estoque de multas das operadoras no país, o que resultou na iniciativa de regulamentação do instrumento de TAC para a correção das condutas das operadoras e na realização de investimentos para a superação dos erros que ensejaram as referidas sanções.

Nos últimos anos, entretanto, após grande esforço do regulador das telecomunicações em desenhar os TACs das prestadoras que demonstraram interesse nessa direção, ocorreram fatos que inviabilizaram o prosseguimento do acordo. É possível destacar, como elemento relevante no processo de aprovação, com ressalvas, dos TACs, as manifestações do Tribunal de Contas da União (TCU), por meio do Acórdão no 2121/2017, que acabaram por se tornar verdadeiras barreiras ao prosseguimento dos TACs.

A sistemática definida pela regulamentação para a celebração dos TACs tem contribuído para a geração de problemas competitivos no setor de telecomunicações, uma vez que outras prestadoras concorrentes dos potenciais celebrantes dos TACs sentem-se prejudicadas por serem objeto de uma potencial competição "financiada" com recursos públicos, o que evidencia a existência de um problema de informação assimétrica entre a empresa e o agente regulador. Esse problema, por sua vez, pode ser enfrentado pelo estabelecimento de um mecanismo de mercado (leilão) que supere eventuais argumentos como os destacados anteriormente, seja por parte de órgãos de controle, seja por competidores no mercado de telecomunicações.

Diante do insucesso da atuação regulatória, o presente trabalho se ocupa exatamente 
em apresentar uma proposta tecnicamente robusta e inovadora que permita superar os entraves à efetiva celebração dos TACs, identificados até o presente momento, e favoreça a expansão dos investimentos no setor, tão necessários e desejados que, certamente, contribuirão para o desenvolvimento do país.

Para além do âmbito dos TACs da Anatel, este artigo pode servir de referência para os demais órgãos da administração pública que venham a ter interesse na utilização de mecanismos de solução negociada, através de um mecanismo que seja apto a lidar com potenciais problemas de informação e gere incentivos compatíveis com os objetivos do poder público que, em última análise, é responsável por incorporar as demandas da sociedade.

A principal contribuição da pesquisa é mostrar que mecanismos de leilão podem ser usados para elucidar de forma ótima a taxa de conversão de dívida em investimento (taxa de abatimento de dívida), que deverá ser usada para cada projeto de investimento a ser proposto pela Anatel às operadoras. Mais ainda, esta pesquisa inova ao vislumbrar um mecanismo que faz uso da natureza sequencial das negociações nos TACs de forma a criar endogenamente uma assimetria entre as operadoras participantes, que tem por consequência maximizar o bem-estar social gerado pela conversão de dívida em investimento.

Além desta breve introdução, o estudo do tema proposto está dividido da seguinte maneira. A seção 2 apresenta um maior detalhamento do problema regulatório enfrentado pela Anatel, em especial no que tange à função regulamentadora do processo sancionatório. As seções 3 e 4 congregaram as maiores contribuições teóricas e aplicadas da presente pesquisa. A seção 3 modela a situação financeira das operadoras antes e depois da celebração de um TAC, evidenciando sob que condições, quanto à taxa de transformação de dívida em investimento, uma operadora terá interesse nesse instrumento. Ademais, constrói um modelo formal de leilão com vistas à determinação competitiva da referida taxa como resultado do equilíbrio de Nash bayesiano do jogo correspondente. A seção 4 introduz uma restrição adicional quanto ao desconto máximo que poderá ser concedido, ou seja, limita o fator de conversão, de forma a evitar fatores demasiado generosos para as concessionárias. Mostra que a escolha estratégica desse limite aumenta, em termos esperados, o benefício social do mecanismo; no entanto, há um custo: existe uma probabilidade positiva de que certos leilões terminem sem vencedor, 
ou seja, sem que o projeto de investimento correspondente seja executado. Em seguida, expande a análise para dois leilões sequenciais e discute a possibilidade de um mecanismo inovador que gera uma vinculação endógena entre os dois leilões consecutivos. Essa vinculação é criada oferecendo-se uma vantagem estratégica no segundo leilão para o vencedor do primeiro. A vantagem estratégica torna a vitória no primeiro leilão mais importante para as operadoras, fazendo com que elas façam lances mais agressivos, beneficiando o bem-estar social resultante dos projetos de investimento. A seção conclui observando que o mecanismo sequencial proposto é eficaz no sentido de que o projeto proposto será sempre implementado pela operadora vitoriosa e que, ademais, o novo mecanismo tem o potencial de gerar maior retorno para a Anatel do que o mecanismo clássico de leilão de primeiro preço ou mesmo que o leilão de primeiro preço com preço de reserva otimamente escolhido pelo leiloeiro. Por fim, a seção 5 traz as considerações finais do trabalho.

\section{Sanções e multas regulatórias no setor de telecomunicações}

A Agência Nacional de Telecomunicações (Anatel), desde sua criação, vem trabalhando para propiciar o desenvolvimento do setor de telecomunicações no Brasil, conforme atribuição legal do órgão. Após o processo de privatização ocorrido em julho de 1998, seguiu-se um período importante de regulamentação levado a cabo pelo regulador setorial que visava estabelecer os principais marcos setoriais ${ }^{2}$.

Dentre as principais atribuições da Anatel, podem-se citar as atividades de fiscalização e controle de obrigações ${ }^{3}$. Essas atividades são de grande relevância para a adequada prestação de serviços à sociedade pelos detentores de outorga.

Naquele momento, os principais objetivos do órgão regulador eram estimular a maximização do investimento privado no setor e garantir o cumprimento do Plano Geral de Metas de Universalização (PGMU/1998) ${ }^{4}$, que continha metas ousadas de abrangência

\footnotetext{
${ }^{2}$ Histórico de regulamentações da agência pode ser acessado em https://www.anatel.gov.br/legislacao/.

${ }^{3}$ Lei Geral de Telecomunicações. http://www.planalto.gov.br/Ccivil_03/leis/L9472.htm, acesso em 02/02/2019.

${ }^{4}$ Decreto no 2592 - aprovou o Plano Geral de Metas para a universalização do serviço telefônico fixo comutado prestado em regime público.
} 
e prazos de atendimento do serviço telefônico fixo comutado, em especial quando comparado ao modelo estatal vigente até então.

De fato, conforme explicitamente apresentado na Exposição de Motivos no 231/MC, um dos principais objetivos do processo de reestruturação do setor de telecomunicações era a ampliação da oferta dos serviços de telecomunicações, o que, sem dúvida, requeria um massivo investimento e esforço de gestão das novas prestadoras.

Passado o primeiro ciclo de grandes investimentos e grande expansão das redes de telecomunicações e da oferta de serviços, a atividade regulatória entrou, a partir de 2005, em uma nova fase ${ }^{5}$ : a de garantia dos direitos dos usuários relativamente aos serviços ofertados.

O rápido crescimento na oferta e prestação dos serviços de telecomunicações, após a privatização, favoreceu a ocorrência de falhas na prestação dos serviços, problemas de qualidade e de atendimento aos usuários. De forma a contornar a situação apresentada e a dar um adequado tratamento às demandas dos usuários, a Anatel redefiniu suas prioridades e redirecionou seu foco de atuação para a melhoria da qualidade ${ }^{6}$, tratamento e solução das demandas e reclamações dos consumidores ${ }^{7}$.

Como consequência desse cenário, as prestadoras se viram obrigadas a rever seus procedimentos internos visando se adequarem à regulamentação ${ }^{8}$. Não obstante, iniciouse um processo intenso de recursos administrativos que acarretou, e acarreta, ônus tanto para o regulado como para o regulador, sem, contudo, garantir o esperado benefício aos usuários dos serviços de telecomunicações.

Diante deste cenário, com base em dispositivos constitucionais e legais, a Anatel iniciou um trabalho de avaliação do marco regulatório sobre as metodologias de sanção e,

5 Prorrogação dos contratos de concessão. https://www.anatel.gov.br/Portal/verificaDocumentos/documento. asp? numeroPublicacao=116482\&assuntoPublicacao=null\&caminhoRel=null\&filtro=1\&documentoPath=biblioteca/ releases/2005/release_22_12_2005ad.pdf

6 Regulamento de qualidade. https://www.anatel.gov.br/legislacao/resolucoes/2005/141-resolucao-411, acesso em 06/01/2019.

\footnotetext{
7 Plano de ação pró-usuários: https://www.anatel.gov.br/Portal/exibirPortalPaginaEspecial.do?org.apache.struts.taglib. html.TOKEN=40ed745c839ccf3701f51e8a0d13e8c9\&acao=carregaPasta\&codItemCanal=1804\&pastaSelecionada=2999 acesso em 05/01/2019.

${ }^{8}$ Diferentes informes e análises do Conselho Diretor da Anatel: Informes nos 424/2011-PBCPP/PBCP, de 03/11/2011, 159/2012/PBCPP/PBCP, de 14/05/2012, Análise 003/2014-GCRZ de 09/01/2014.
} 
posteriormente, para a celebração de termo de ajustamento de conduta.

Relativamente às metodologias de definição das multas, nos primeiros anos da atividade regulatória, era possível observar uma quantidade significativa de métodos para definição de sanção de multa. A ausência de uma padronização das metodologias de sanção associada à ausência de um adequado tratamento das demandas, no sentido de gerar ações resolutivas para as condutas infratoras, levou a um aumento expressivo do volume das multas aplicadas, conforme divulgado em diversos veículos de comunicação. Em alguns casos o volume de multas aplicadas chegou a corresponder a uma fração importante do valor de mercado de algumas prestadoras.

Ao longo do tempo, a agência, considerando as contribuições da sociedade, via mecanismo de consulta pública, revisitou o conteúdo do regulamento de sanções e as diferentes metodologias existentes para os diferentes tipos de infrações.

Na prática, a revisão da regulamentação dos serviços de telecomunicações, de qualidade e de controle de obrigações associadas à dinâmica de sancionamento, estava, há algum tempo, dando sinais de que a prestação dos serviços de telecomunicações, dentro dos parâmetros regulamentares vigentes, não vinha produzindo um ambiente de satisfação plena ao consumidor, sobretudo pelo fato de que a regulamentação não estava em plena sintonia com os anseios ou os requisitos de qualidade percebidos pela sociedade.

Referido regulamento previa em seu artigo 5ㅇ a possibilidade de celebração, com os infratores, de compromissos de ajustamento de conduta (TAC) às exigências legais a serem regulamentados em instrumento próprio.

Por outro lado, a Lei no 7.347, de 24 de julho de 1985 (Lei da Ação Civil Pública), estabeleceu a legitimidade das autarquias para tomar dos interessados compromisso de ajustamento de sua conduta às exigências legais, mediante cominações, que terá eficácia de título executivo extrajudicial (art. 5으, inciso IV c/c art. 5ㅇ, § 6으).

Assim, quando combinada com as competências da Anatel dirigidas à proteção ao consumidor, direitos coletivos e com a defesa da ordem econômica e da economia popular (art. 1으, II e V, da Lei no 7.347/85 c/c art. 5으, LGT), bem como repressão das infrações a direitos dos usuários (art. 19ㅇ, XVIII, LGT), entendeu a agência possuir também 
a competência para a celebração de termos de ajustamento de conduta, ou seja, a adoção de medidas substitutivas à sanção de multa, de modo a buscar mais eficiência na defesa do interesse público.

Da documentação analisada, é possível constatar que, apesar dos esforços envidados pelo órgão regulador $^{9}$, o mecanismo proposto padece da necessidade de robustez, sobretudo no que tange ao grande potencial de "erro de medida" quando do cálculo ou validação dos valores de dos projetos, tanto daqueles pertencentes ao rol a ser disponibilizado pela agência, como daqueles a serem submetidos pelas prestadoras.

A despeito da capacidade do corpo técnico da Anatel, sabe-se que a relação regulado-regulador é permeada de assimetria de informação (LAFFONT; TIROLE, 1999), o que torna difícil para o regulador ser assertivo/preciso quanto ao cálculo dos dos planos de negócios para cada projeto.

Os erros de medida ou avaliação no caso dos leilões de radiofrequências podem ser tolerados, pois o procedimento licitatório tem a capacidade de corrigi-los, isto é, o leilão recupera o mecanismo de mercado, produzindo uma correta precificação e a maximização do lucro para o vendedor ou a eficiência de Pareto, no sentido de que o objeto é destinado ao agente que atribui maior valor (VARIAN, 2000; KRISHNA, 2002; KRISHNA, 2009).

Nesse ínterim, torna-se importante destacar que a solução negocial apresentada pelo órgão regulador para a celebração dos TACs tem grande potencial de ser afetada por problemas de erro de estimações, bem como de natureza moral, conforme situações análogas que vêm sendo averiguadas pelo judiciário nos últimos meses, em que o excesso de discricionariedade dos agentes públicos vem produzindo resultados negativos para o país.

A fragilidade da sistemática negocial proposta pela Anate ${ }^{10}$ pode ser contornada pela adoção de mecanismo que emule um ambiente de mercado, próprio para situações

\footnotetext{
${ }^{9}$ Resolução no 629, de 16/12/2013 - aprova o regulamento de celebração e acompanhamento de termo de compromisso de ajustamento de conduta (TAC), https://www.anatel.gov.br/legislacao/resolucoes/2013/680-resolucao-629, acesso em 20/7/2015.

${ }^{10}$ Resolução no 629, de 16/12/2013 - Aprova o regulamento de celebração e acompanhamento de Termo de compromisso de ajustamento de conduta (TAC), https://www.anatel.gov.br/legislacao/resolucoes/2013/680-resolucao-629, acesso em 20/7/2015.
} 
em que não existe um mercado de fato para transação dos bens a serem ofertados, sendo a definição de preços dos referidos bens de difícil mensuração.

Como é apresentada na literatura econômica ${ }^{11}$, a atividade regulatória é permeada de problemas de informação. No caso em tela percebia-se que a proposta em consulta não buscava mitigar os problemas de assimetria de informação e seleção adversa, o que aumentava as chances de alocações ineficientes dos recursos, exatamente um dos problemas que se visava corrigir e que, em certa medida, está contido nas manifestações do Tribunal de Contas da União.

Nesse sentido, o presente trabalho busca contribuir com o processo de implementação do TAC proposto pela Anatel, podendo servir de referência para os demais órgãos da administração pública que venham a ter interesse na utilização de solução negociada, através da proposição de um mecanismo que seja apto a lidar com potenciais problemas de informação e gere incentivos compatíveis com os objetivos do poder público, que, em última análise, é responsável por incorporar as demandas da sociedade.

\section{Leilões para a determinação endógena objetiva da taxa de desconto da multa a ser usada nos projetos de investimento}

Conforme discutido anteriormente, um dos problemas mais complexos associados ao mecanismo de TAC na Anatel diz respeito à determinação da taxa de desconto da multa de uma operadora que se candidata a fazer um investimento proposto pela Anatel. Diante dessa dificuldade, e inclusive com o objetivo de blindar a instituição de futuros questionamentos quanto à isenção na decisão da taxa de desconto, este trabalho propõe o uso do mecanismo geral de leilão ou, mais especificamente, do mecanismo de leilão para se obter uma determinação endógena e objetiva dessa taxa de desconto.

O mecanismo proposto funciona da seguinte forma. Inicialmente, a Anatel determina que projeto de investimento faz-se necessário no setor, de forma a maximizar o bem-estar social gerado pelo mercado de telecomunicações. Em seguida, avalia o valor presente líquido $(V P L)$ esperado desse investimento. Caso o $V P L$ esperado desse investimento

\footnotetext{
11 JeHLE; RENY (2011), MAS COLLEL ${ }^{(1995),}$ VARIAN ${ }^{(1992) .}$
} 
seja positivo, então não há necessidade de incluí-lo nos projetos a serem estimulados pelo mecanismo de TAC: as operadoras naturalmente investirão nesse projeto. No entanto, caso exista divergência entre o benefício social de um projeto e seu valor presente, de forma que este último seja negativo, então as operadoras não terão interesse em levar adiante esse projeto. É nesse caso que a troca de dívida por investimento pode ser usada de forma a induzir as firmas a implementarem o projeto socialmente desejável.

Suponha, pois, que a Anatel tenha decidido que o projeto $\mathrm{P}$ será prioritário e que esse projeto possua $V P L$ esperado negativo. Seja $c$ o custo do projeto P. Então a Anatel oferecerá reduzir dívida da operadora que aceite implantar esse projeto, desde que essa operadora seja vitoriosa em leilão que determinará a taxa de desconto da multa.

O leilão será implantado da seguinte forma. Cada operadora $i$ participante do leilão entregará seu lance secreto, em envelope lacrado, contendo a taxa de desconto $d_{i}>0$ pela qual aceita transformar dívida em investimento no projeto P. Portanto, esse lance corresponde a quantos reais de desconto de sua dívida a operadora exige por real do investimento $c$. Se, por exemplo, $d_{i}=0.5$, isso significa que a operadora $i$ está disposta a aceitar um desconto de um real em sua dívida para cada dois reais gastos por ela no projeto $\mathrm{P}^{12}$. A Anatel abrirá então os envelopes lacrados e anunciará como vencedora a firma $i$ que tiver oferecido o menor valor para $d_{i}>0$, ou seja, aquela que estiver disposta a executar o investimento com a menor redução total de sua dívida.

Nas próximas seções deste artigo, modela-se inicialmente como cada firma avalia o menor desconto que ainda lhe é lucrativo fazer para implementar o investimento. Esse valor caracterizará cada firma e, por isso, será chamado de "tipo" da firma $i$. Em seguida, analisa-se um leilão de primeiro preço e encontra-se a taxa de desconto de equilíbrio sob hipóteses específicas a respeito da distribuição dos tipos das operadoras e, finalmente, concluir-se-á calculando o custo esperado para a sociedade associado a esse mecanismo de leilão, que se materializa na forma da renúncia fiscal embutida no mecanismo de troca de dívida por investimento.

\subsection{0 tipo de uma operadora}

\footnotetext{
${ }^{12}$ Espera-se que a Anatel inclua no leilão o limite superior para $d_{i}, d_{i} \leq 1$, ou seja, o máximo que a Anatel autorizará será um desconto de um real por real investido. No entanto, essa hipótese não é necessária no presente modelo teórico.
} 
De forma a simplificar a análise, supomos a existência de apenas duas operadoras, $i=1,2$.

Considere inicialmente a situação das operadoras antes do TAC.

Seja $l_{i}, i=1,2$, o valor (presente) da operadora $i$, não se incluindo nesse cálculo a multa devida nem qualquer consideração sobre o projeto P. Seja ainda $m_{i}, i=1,2$ o valor total da multa acumulada pela operadora $i$. Suponha que a operadora $i$ estime que a probabilidade de vir a ter que pagar sua multa pela via judicial ou administrativa seja $p_{i}$ . Então o valor esperado do custo da multa é $p_{i} m_{i}$. Portanto, o valor atual esperado da operadora $i$, ou seja, antes da inovação do mecanismo do TAC, é dado por:

$$
v_{i}=l_{i}-p_{i} m_{i}, \quad i=1,2
$$

A Tabela 1 a seguir mostra o valor estimado, $l_{i}$, das principais operadoras de telecomunicação, até abril de 2018. Verifica-se que a Oi estava com um valor de mercado, em 2013, de $\mathrm{R} \$ 6.464$ milhões, uma queda de mais de 50\% em relação ao ano anterior. Tendo em vista o montante de multas aplicado às empresas do setor, apresentado a seguir, tem-se que sua representatividade é bastante expressiva quando comparada com os valores de mercado apresentados, exceto para o caso do grupo Telefônica. Ressalte-se que o expressivo aumento do valor de mercado da Telefônica em 2011, vis-à-vis 2010, deve-se à fusão com a operadora móvel Vivo. Relativamente à probabilidade de efetiva arrecadação das multas, $p_{i}$, Miranda (2011) identificou alta probabilidade de negação dos recursos de primeira instância às multas aplicadas pelo órgão regulador, o que sugere que a chance de perda das firmas reguladas pode ser elevada.

Já a Tabela 2 apresenta o valor aproximado das multas das principais concessionárias em setembro de 2018. Os dados foram obtidos do Relatório do Sistema de Créditos da Anatel. 
Tabela 1 - Evolução anual do valor de mercado das principais empresas (R\$ milhões, valores correntes)

\begin{tabular}{|c|c|c|c|c|c|c|c|c|c|c|c|c|c|c|}
\hline Empresa & 2007 & 2008 & 2009 & 2010 & 2011 & 2012 & 2013 & 2015 & 2016 & 2017 & jan/18 & fev/18 & $\mathrm{mar} / 18$ & $a b r / 18$ \\
\hline $\begin{array}{l}\text { Telefônica } \\
\text { Brasil* }\end{array}$ & 23.101 & 21.670 & 21.100 & 20.816 & 56.850 & 53.133 & 48.618 & 59.447 & 70.148 & 77.974 & 85.172 & 80.772 & 81.681 & 80.214 \\
\hline Vivo & 15.744 & 10.415 & 21.765 & 29.004 & - & - & - & & & & & & & \\
\hline TIM Part. & 16.035 & 8.479 & 13.648 & 14.738 & 22.339 & 19.825 & 29.809 & 16.608 & 18.957 & 31.716 & 32.684 & 34.137 & 34.863 & 38.615 \\
\hline Oi & - & - & - & - & - & 14.455 & 6.464 & 1.9112 & $2.112^{* *}$ & 2.972 & 3.077 & 3.192 & 3.207 & 3.079 \\
\hline $\begin{array}{l}\text { Telemar } \\
\text { (TNL) }\end{array}$ & 20.676 & 13.492 & 15.874 & 10.564 & 9.100 & - & - & & & & & & & \\
\hline $\begin{array}{l}\text { Telemar } \\
\text { Norte } \\
\text { Leste }\end{array}$ & 20.676 & 13.492 & 15.874 & 12.391 & 16.918 & - & - & & & & & & & \\
\hline $\begin{array}{l}\text { Brasil } \\
\text { Telecom }\end{array}$ & 13.445 & 18.099 & 12.289 & 7.916 & 6.726 & - & - & & & & & & & \\
\hline $\begin{array}{l}\text { Embratel } \\
\text { Part. }\end{array}$ & 6.763 & 8.413 & 15.783 & 10.670 & 9.847 & 13.311 & 9.425 & & & & & & & \\
\hline NET & 8.199 & 5.544 & 7.773 & 7.538 & 5.820 & 9.444 & 8.458 & & & & & & & \\
\hline Total & 124.639 & 99.604 & 124.106 & 113.637 & 127.600 & 110.168 & 102.774 & 77.966 & 91.217 & 112.662 & 120.933 & 118.101 & 119.751 & 121.908 \\
\hline
\end{tabular}

Tabela 2 - Valores de multas não arrecadados (R\$, valores correntes, setembro de 2018)

\begin{tabular}{|cc|}
\hline Empresas & Montante não arrecadado \\
\hline Empresa A & $4,5 \mathrm{BI}$ \\
\hline Empresa B & $35,5 \mathrm{Ml}$ \\
\hline Empresa C & $411,11 \mathrm{Ml}$ \\
\hline Empresa D & 445 \\
\hline
\end{tabular}

Fonte: detalhamento do Relatório do Sistema de Créditos da Anatel.

Vale notar que, se $m_{i}$ for muito elevado, como parece ser o caso atual para algumas operadoras, então é possível que $l_{i}-m_{i}<0$. Portanto, se $p_{i}$ for suficientemente elevado (próximo de 1), o valor esperado da operadora poderá ser negativo.

Considere agora a situação das operadoras após ser introduzida a possibilidade do TAC e a oferta do projeto de investimento P de custo $C$. Devido ao elevado endividamento das operadoras, supomos que o custo de $\mathrm{P}, c$, está bem abaixo da dívida de ambas as empresas (multas acumuladas), $m_{1}, m_{2} \gg c$. 
Em princípio, o projeto de investimento $\mathrm{P}$ gerará um retorno diferenciado para cada operadora, devido à sua capacidade tecnológica e gerencial de se beneficiar desse investimento. Suponha que $\mathrm{P}$ gere um retorno à operadora $i$ dado pela função $g_{i}(c)$ , suposta estritamente crescente e côncava. Então $g_{i}(c)-c$ caracteriza o retorno líquido ou $V P L$ do projeto para a firma $i$. Se $g_{i}(c)-c \geq 0$, então será do interesse da operadora participar do TAC qualquer que seja o valor do desconto $d$. Por outro lado, se $g_{i}(c)-c<0$ a firma não terá interesse em desenvolver o projeto, apesar de seu retorno social, caso ela não seja compensada, via redução de dívida, por exemplo.

Seja $G_{i}=c-g_{i}(c)$ uma medida do valor presente líquido do prejuízo do projeto para a operadora, que supomos positivo, ou seja, a operadora não executaria esse projeto caso não houvesse o benefício do TAC. O parâmetro $G_{i}$ é chamado de tipo da firma $i$, e é sua informação privada. É importante notar que a Anatel possui capacidade técnica para estimar o valor esperado do $V P L$ para as firmas, e a instituição o fará para determinar a escolha do projeto P. No entanto, existe clara e efetiva assimetria de informação entre o órgão regulador e a empresa regulada, sendo essa toda a essência da teoria moderna da regulação econômica iniciada em Baron e Myerson (1982).

Do ponto de vista da Anatel (bem como da outra operadora), o tipo $G_{i}$ da operadora $i$ é uma variável aleatória distribuída num intervalo $T_{i}$ de acordo com uma função de distribuição de probabilidades $F_{i}\left(G_{i}\right)$, de forma que no leilão pode ser modelada como um jogo bayesiano entre as duas operadoras concorrentes.

Suponha que a operadora $i$ vença o leilão com a taxa de desconto $d_{i}$. Então o novo valor esperado da firma será $v_{i}^{\prime}=l_{i}+g_{i}(c)-c-p_{i}\left(m_{i}-d_{i} c\right)$, ou ainda,

$$
v_{i}^{\prime}=l_{i}-p_{i} m_{i}+p_{i} d_{i} c-G_{i}=v_{i}+p_{i} d_{i} c-G_{i}
$$

Portanto, um desconto $d_{i}$ somente será vantajoso para a operadora se $v_{i}^{\prime} \geq v_{i}$, ou ainda,

$$
d_{i} \geq \frac{G_{i}}{p_{i} c}=\frac{1}{p_{i}}\left[1-\frac{g_{i}(c)}{c}\right]
$$


A expressão acima apresenta o lance mínimo que será feito pela operadora $i$ e diz que, quanto maior for o $V P L$ do prejuízo do projeto para a firma, tanto maior será sua exigência de desconto para firmar um TAC com a Anatel. Além disso, quanto maior for a estimativa da firma de que terá realmente que pagar sua dívida, $p_{i}$, tanto menor será sua exigência de desconto. Finalmente, quanto maior for o benefício do projeto $g_{i}(c)$ relativamente ao seu custo, menor será sua exigência de desconto. Em particular, se o benefício for tanto que $G_{i}<0$, então a firma está disposta a fazer/executar o projeto independentemente de qualquer desconto em sua dívida. Por essa razão, supusemos neste trabalho que $G_{i}>0$, ou seja, é, sim, necessário um desconto na dívida da operadora para que ela tenha interesse em executar o projeto de investimento $P$.

Vale notar o importante papel das instituições: quanto maior for a probabilidade de a operadora se ver forçada a pagar sua dívida, ou seja, quanto mais atuantes forem as instituições administrativas e jurídicas no sentido de assegurar o pagamento da dívida, menor será o desconto que a operadora exigirá para executar o projeto. Trata-se de uma materialização do conhecido "custo país".

\subsection{Jogo de leilão para precificação do TAC e seu equilíbrio de Nash bayesiano}

Nesta seção, construímos o jogo de leilão entre as duas operadoras e determinamos seu equilíbrio de Nash bayesiano. A forma normal ou forma estratégica do jogo é definida por: o conjunto de jogadores; os conjuntos dos tipos dos jogadores e as distribuições dos tipos; os conjuntos das possíveis ações dos jogadores; e os payoffs ex-post correspondentes.

No presente modelo há dois jogadores, $N=\{1,2\}$. Por simplicidade, escolhemos o conjunto de tipos como sendo o intervalo $[0,1]: \Gamma_{1}=[0,1] ; \Gamma_{2}=[0,1]$ correspondendo ao $V P L$ do custo (prejuízo) do projeto e supomos que os tipos se encontram uniformemente distribuídos nesses intervalos, ou seja $F_{1}\left(G_{1}\right)=G_{1} ; F_{2}\left(G_{2}\right)=G_{2}$. Vale notar que não há perda de generalidade em se escolher o intervalo [0,1], uma vez que, se o prejuízo máximo fosse $\gamma>1$, bastaria uma mudança de escala na medida monetária para se voltar ao intervalo [0,1], por exemplo, se $\gamma=R \$ 1000000$, consideraríamos que o custo está medido em milhões de reais. Ademais, inicialmente supomos que a Anatel não limita o desconto máximo, de forma que os conjuntos de ações correspondem ao intervalo não negativo: $A_{1}=[0,+\infty) ; A_{2}=[0,+\infty)$. 
No presente modelo há dois jogadores, . Por simplicidade, escolhemos o conjunto de tipos como sendo o intervalo $[0,1]$ : correspondendo ao do custo (prejuízo) do projeto e supomos que os tipos se encontram uniformemente distribuídos nesses intervalos, ou seja . Vale notar que não há perda de generalidade em se escolher o intervalo, uma vez que, se o prejuízo máximo fosse , bastaria uma mudança de escala na medida monetária para se voltar ao intervalo, por exemplo, se , consideraríamos que o custo está medido em milhões de reais. Ademais, inicialmente supomos que a Anatel não limita o desconto máximo, de forma que os conjuntos de ações correspondem ao intervalo não negativo: .

Finalmente, os payoffs ex-post, quando a operadora 1 é do tipo $G_{1}$ e escolhe o desconto $\delta_{1}$ e a operadora 2 é do tipo $G_{2}$ e escolhe o desconto $\delta_{2}$, são dados por:

$$
\begin{aligned}
& u_{1}\left(\left(\delta_{1}, \delta_{2}\right),\left(G_{1}, G_{2}\right)\right)=\left\{\begin{array}{ccc}
v_{1}^{\prime} & \text { se } & \delta_{1}<\delta_{2} \\
\frac{v_{1}^{\prime}}{2}+\frac{v_{1}}{2} & \text { se } & \delta_{1}=\delta_{2} \\
v_{1} & \text { se } & \delta_{1}>\delta_{2}
\end{array}\right. \\
& u_{2}\left(\left(\delta_{1}, \delta_{2}\right),\left(G_{1}, G_{2}\right)\right)=\left\{\begin{array}{ccc}
v_{2}^{\prime} & \text { se } & \delta_{1}>\delta_{2} \\
\frac{v_{2}^{\prime}}{2}+\frac{v_{2}}{2} & \text { se } & \delta_{1}=\delta_{2} \\
v_{2} & \text { se } & \delta_{1}<\delta_{2}
\end{array}\right.
\end{aligned}
$$

Um equilíbrio de Nash bayesiano deste jogo é um par de funções estratégias $\left(d_{1}, d_{2}\right)$, em que $\lambda_{i}: \Gamma_{i} \rightarrow A_{i}$ satisfaz:

(i) Para cada realização do tipo do agente $1, G_{1} \in \Gamma_{1}, d_{1}\left(G_{1}\right)=\delta_{1}$ é a solução do seguinte problema de maximização:

$$
\max _{\delta_{1}} v_{1}^{\prime} \times \operatorname{Pr}\left[\delta_{1}<d_{2}\left(G_{2}\right)\right]+\frac{1}{2}\left(v_{1}^{\prime}+v_{1}\right) \times \operatorname{Pr}\left[\delta_{1}=d_{2}\left(G_{2}\right)\right]+v_{1} \times \operatorname{Pr}\left[\delta_{1}>d_{2}\left(G_{2}\right)\right]
$$

(ii) Para cada realização do tipo do agente $2, G_{2} \in \Gamma_{2}, d_{2}\left(G_{2}\right)=\delta_{2}$ é a solução do seguinte problema de maximização:

$$
\max _{\delta_{2}} v_{2}^{\prime} \times \operatorname{Pr}\left[\delta_{2}<d_{1}\left(G_{1}\right)\right]+\frac{1}{2}\left(v_{2}^{\prime}+v_{2}\right) \times \operatorname{Pr}\left[\delta_{2}=d_{1}\left(G_{1}\right)\right]+v_{2} \times \operatorname{Pr}\left[\delta_{2}>d_{1}\left(G_{1}\right)\right]
$$


Nesse modelo supomos, ainda por simplicidade, que os dois operadores possuem as mesmas estimativas quanto à probabilidade de serem forçados (administrativa ou judicialmente) a pagar suas dívidas: $p_{1}=p_{2}=p$, ou seja, não há qualquer tipo de favoritismo quanto à impunibilidade do pagamento da dívida ${ }^{14}$.

O único equilíbrio de Nash bayesiano simétrico estritamente crescente é encontrado seguindo as técnicas-padrão ${ }^{15}$, desenvolvidas em detalhe no Apêndice, e é dado por:

$$
d_{1}\left(G_{1}\right)=\frac{1+G_{1}}{2 p c} ; \quad d_{2}\left(G_{2}\right)=\frac{1+G_{2}}{2 p c}
$$

Vale notar que o equilíbrio é eficiente no seguinte sentido. Em primeiro lugar, o vencedor do leilão é aquela operadora que tem o menor $V P L$ do custo de implantação do projeto P: $d_{1}\left(G_{1}\right)<d_{2}\left(G_{2}\right) \Leftrightarrow G_{1}<G_{2}$. Em segundo lugar, o projeto sempre é executado, ou seja, não há risco de o leilão ser concluído sem nenhuma operadora se interessar em assinar o TAC com a Anatel. Esta última propriedade é extremamente importante, pois o objetivo primordial do TAC é justamente encontrar formas de transformar as dívidas das operadoras, consideradas essencialmente impagáveis, em projetos que tenham o maior retorno social possível. Caso o projeto não seja implementado, o problema das dívidas continua, sem nenhum ganho para sociedade.

É importante observar ainda que, como $G_{i} \leq 1$, então $\frac{1+G_{i}}{2 p c} \geq \frac{G_{i}}{2 p c}$, que é a exigência de desconto mínima que o jogador $i$ estaria disposto a aceitar para implantar o projeto. Assim, em equilíbrio as operadoras exigem um desconto maior do que aquele que elas estariam dispostas a aceitar caso estivéssemos em um contexto de informação completa. Em outras palavras, o mecanismo de leilão permite um desconto da dívida acima do mínimo que seria necessário para garantir a implantação do projeto caso houvesse informação completa sobre o tipo das operadoras. Trata-se da renda adicional que os jogadores ganham por possuírem informação privilegiada sobre seus tipos e é conhecida na literatura por renda informacional. A existência de renda informacional em contexto de regulação econômica é um fenômeno conhecido desde o trabalho seminal de Baron e Myerson (1982). A próxima seção estima o benefício social líquido com a implantação do mecanismo de leilão. 


\subsection{O benefício social líquido e custo esperado do leilão de conversão de dívida em investimento}

Seja $B$ o benefício social gerado pelo investimento de custo $c$ acima descrito. Se $B>c$, então, do ponto de vista social, o investimento deve ser feito, pois seu retorno social excede seu custo. Esse deve ser o critério social para que a Anatel decida estimular o investimento.

Do ponto de vista do governo, no entanto, representado pela Anatel, o benefício social líquido do investimento é medido pela diferença entre seu benefício social $B$ e o custo coberto pelo governo por meio da renúncia a receber as multas devidas.

Considerando que as multas somente seriam pagas com a probabilidade $p$, caso o leilão seja usado, podemos calcular o benefício social esperado líquido do projeto leiloado conforme a seguir.

O benefício líquido esperado para o governo quando a operadora 1 vence é:

$$
\int_{0}^{1} \int_{G_{1}}^{1}\left[B-p d_{1}\left(G_{1}\right) c\right] d G_{2} d G_{1}=\int_{0}^{1} \int_{G_{1}}^{1}\left[B-p c \frac{1+G_{1}}{2 p c}\right] d G_{2} d G_{1}=\frac{B}{2}-\frac{1}{3}
$$

Portanto, por simetria, o benefício líquido esperado para o governo, considerando as duas operadoras, é $B-\frac{2}{3}$.

Vale notar que, caso a Anatel pudesse observar exatamente o VPL (negativo) das firmas e atribuir o projeto à firma com $V P L$ de menor valor absoluto (menor custo possível), então o benefício líquido esperado para o governo quando a operadora 1 tem o menor custo seria:

$$
\int_{\text {Po }}^{1} \int_{0}^{1}\left[B-p c \frac{G_{1}}{2 p c}\right] d G_{2} d G_{1}=\frac{B}{2}-\frac{1}{12}
$$

Poßtanto, novamente pela simetria, o benefício líquido esperado para o governo, considerando as duas operadoras seria $B-\frac{1}{6}$.

Em termos de custo, o custo esperado mínimo possível para o governo seria $\frac{1}{6}$ 
, lembrando que o custo esperado para uma empresa é $\frac{1}{2}$. No entanto, caso não seja definido um mecanismo objetivo de precificação, uma negociação aberta entre a Anatel e uma operadora poderia levar a custos extremamente elevados para o governo, podendo inclusive atingir o custo máximo de $G_{i}=1$, que corresponde a um aumento de $500 \%$ sobre o custo mínimo.

A introdução do leilão permite o controle de forma objetiva do custo esperado dos TACs para o governo, que é reduzido para $\frac{2}{3}$, que corresponde a ainda $300 \%$ sobre o custo mínimo, mas a apenas 33\% sobre o custo médio da operadora.

O restante deste trabalho se dedica a analisar variações do modelo básico de leilão sugerido, de forma a se reduzir ainda mais o custo dos TACs para o governo. No que se segue, postularemos que $1<B<2$, ou seja, o benefício social é maior do que o maior custo presente líquido possível do projeto para as operadoras (lembrando que $G_{i} \in[0,1]$ ), mas é menor que duas vezes esse custo máximo. A restrição diz que o benefício social supera o maior valor presente do prejuízo para uma operadora em implantar o projeto de investimento, mas que esse benefício social não é grande demais a ponto de tornar o investimento exageradamente vantajoso para a sociedade. O limite superior de $B$ tornará relevante a discussão a respeito da imposição de uma taxa máxima de desconto nos leilões de conversão ${ }^{16}$.

\section{Desconto máximo otimamente determinado e leilões sequenciais}

Consideramos agora que a Anatel estabelece um desconto máximo autorizado para as operadoras participando de um leilão de conversão de dívida em investimento.

\footnotetext{
${ }^{16}$ Caso tivéssemos $B<1$, então não valeria a pena para a sociedade apoiar esse projeto, uma vez que o benefício seria menor que o custo. Por outro lado, caso $B \gg 1$ fosse muito elevado, e caso fosse maior que 2 , então o projeto seria tão benéfico para a sociedade que não conviria estabelecer qualquer tipo de limite ao desconto, conforme fica claro na seção seguinte. Ou seja, só é relevante se preocupar com a escolha ótima do limite ao desconto quando o benefício social do projeto não é extremamente elevado.
} 
Seja $\Delta>0$ essa taxa máxima, de forma que $d_{i}\left(G_{i}\right) \leq \Delta, \forall G_{i} \in[0,1]$, em que $G_{i}$ é o tipo da operadora $i=1,2$.

Então, se a operadora $i$ for do tipo $G_{i}>p c \Delta$, preferirá não fazer lance algum, não tendo interesse em vencer o leilão. Se $p c \Delta>1$, então $G_{i}<p c \Delta, \forall G_{i} \in[0,1]$ e a restrição se torna irrelevante. Portanto, supomos que $p c \Delta<1$, de forma que existirão alguns tipos de operadoras que desistirão do leilão.

Por outro lado, quando $G_{i} \leq p c \Delta$, então a operadora $i$ resolverá o mesmo problema já tratado anteriormente. Observando a condição de contorno correspondente a esse problema ${ }^{17}$, chega-se à seguinte expressão para a função de lance em equilíbrio:

$$
d_{i}\left(G_{i}\right)=\frac{1+G_{i}}{2 p c}-\frac{(1-p c \Delta)^{2}}{2 p c} \frac{1}{1-G_{i}}, G_{i} \in[0, p c \Delta], i=1,2
$$

Comparando-se as expressões em (4) e em (5), nota-se que a restrição ao desconto tem por efeito uma redução no desconto solicitado pelas operadoras em equilíbrio, o que sugere um benefício para a Anatel. Por outro lado, conforme discutido, se a operadora $i$ for do tipo $G_{i}>p c \Delta$, então ela preferirá não investir, o que pode reduzir o benefício social esperado do TAC. A seguir calcula-se o valor ótimo do desconto, aquele que maximiza o retorno social esperado para o governo.

Dada a restrição de desconto $\Delta$, o benefício líquido esperado para o governo quando a operadora 1 vence é:

$$
\begin{gathered}
\int_{0}^{p c \Delta} \int_{G_{1}}^{1}\left[B-p c d_{1}\left(G_{1}\right)\right] d G_{2} d G_{1}=\frac{1}{2} \int_{0}^{p c \Delta} \int_{G_{1}}^{1}\left[2 B-\left(1+G_{1}\right)+\frac{(1-p c \Delta)^{2}}{1-G_{1}}\right] d G_{2} d G_{1} \\
=B p c \Delta-\left[\frac{B}{2}+1\right](p c)^{2} \Delta^{2}+\frac{2}{3}(p c)^{3} \Delta^{3}
\end{gathered}
$$

Considerando que $B<2$, a expressão acima é maximizada em $\Delta=\frac{B}{2 p c}<\frac{1}{p c}$. 
Portanto, o benefício líquido esperado para o governo, quando a operadora 1 vence, com a restrição ótima ao desconto é:

$$
\frac{1}{4} B^{2}\left[3-\frac{1}{6} B\right]
$$

Destarte, novamente pela simetria, o benefício líquido esperado para o governo, considerando as duas operadoras com a restrição ótima ao desconto, é:

$$
\frac{1}{2} B^{2}\left[3-\frac{1}{6} B\right]
$$

Comparando o bem-estar social quando é introduzida a restrição com a situação anterior, conclui-se que, para $B<12$ - o que é o caso aqui $(B<2)$-, há um efetivo ganho no benefício líquido com a introdução da restrição ao desconto.

Vale notar, no entanto, que esse aumento no benefício ocorre ao custo de existir uma gama de possíveis valores das operadoras que levarão ao fracasso ex-post do leilão. Isso ocorrerá sempre que ambos os custos presentes líquidos de ambas as operadoras forem maiores que $p c \Delta=\frac{B}{2}$, i.e., $G_{i}>\frac{B}{2}, i=1,2$. Note que, quanto menor for o benefício bruto $B$, maior será a probabilidade de o leilão se concluir sem nenhum vencedor. Portanto, deve-se medir com o devido cuidado o custo político de um leilão fracassado. Caso esse custo seja elevado, melhor será não incluir um limite à taxa de desconto, uma vez que, sem o limite, o mecanismo se torna eficiente no sentido de que o projeto de investimento será sempre implantado.

Assim, a introdução de um limite ao desconto traz consigo um aumento no benefício esperado líquido do projeto para o governo, mas, ao mesmo tempo, torna o mecanismo de seleção ineficiente no sentido de que haverá situação em que o projeto não será implementado.

Até o momento estudamos um modelo de um leilão de um único objeto. No entanto, no contexto dos TACs da Anatel, dado o enorme montante das dívidas das operadoras, é natural se esperar que os TACs serão implementados por meio de vários projetos diversos e específicos de investimento. Caso sejam usados leilões para a seleção de cada projeto, 
a teoria adequada se encaixa na teoria de leilões de objetos múltiplos, que podem ser implementados de forma simultânea, em que todos os objetos são vendidos ao mesmo tempo, ou de forma sequencial, em que há uma sequência na venda dos objetos (Menezes, 1998). A não ser no caso bem simples em que todos os objetos são idênticos e que cada comprador tem interesse por apenas uma unidade desses objetos (objetos idênticos com demanda unitária), esses leilões tendem a ser muito mais complexos e a teoria correspondente encontra-se bem menos desenvolvida ${ }^{18}$ (KRISHNA, 2010, caps. 12 a 15). No caso específico em que os leilões são sequenciais e as demandas não são unitárias, pouco se sabe a respeito das estratégias de equilíbrio (KRISHNA 2010, cap. 15). Uma exceção conhecida é Katzman (1999), que encontra equilíbrios simétricos para o caso de dois leilões sequenciais com um total de dois objetos a serem vendidos.

O estudo desenvolvido em Bugarin (2015), por outro lado, lança mão do fato de haver um relacionamento sequencial entre um leiloeiro e os participantes de uma sequência de leilões para ligar um leilão com seu leilão seguinte e, assim, aumentar o benefício esperado do leiloeiro. Esse mecanismo tem a vantagem de garantir que o objeto seja sempre vendido.

Os TACs de conversão de dívida em investimento têm justamente essa característica: existem muitos projetos de investimento, de forma que uma mesma operadora pode fazer uso, mais de uma vez, do mecanismo para abater suas dívidas. Nesse caso, um mecanismo semelhante àquele proposto em Bugarin (2015) poderia ser implantado no mecanismo de leilão proposto neste artigo.

O mecanismo funcionaria da seguinte forma. Inicialmente seria negociado um projeto de (conversão de dívida em) investimento, de acordo com o mecanismo de leilão aqui proposto. $\mathrm{O}$ vencedor desse pleito então levaria consigo uma vantagem estratégica para o pleito seguinte na forma de um benefício $\gamma>0$ na comparação de sua proposta de taxa de desconto com a de seu oponente. Assim, suponha por exemplo que a operadora 1 tenha vencido o primeiro leilão e que as taxas de conversão respectivas no segundo leilão, os lances dos jogadores 1 e 2 , tenham sido respectivamente $\delta_{1}$ e $\delta_{2}$. Então, na regra original, o jogador 1 vence se seu lance for tal que $\delta_{1}<\delta_{2}$. Com a vantagem $\gamma$, no entanto, 1 vencerá sempre que $\delta_{1}<\delta_{2}+\gamma$. Essa vantagem faz com que o vencedor do primeiro leilão possa, no segundo leilão, pedir um desconto maior de sua dívida que o seu 
concorrente e, ainda assim, vencer esse segundo leilão. Portanto, a vantagem torna a vitória no primeiro leilão ainda mais atraente para os dois jogadores, fazendo com que ambos os jogadores façam lances mais agressivos no primeiro leilão. Esses lances mais competitivos devem reverter em ganhos esperados maiores que o estabelecimento de uma regra de desconto máximo.

Não é objetivo deste trabalho desenvolver a teoria por trás do argumento a ser aplicado nos leilões sequenciais. Esse desenvolvimento é deixado aqui como uma sugestão para pesquisas futuras sobre formas de se ajustar o mecanismo de leilão aqui proposto para obter resultados ainda melhores para a Anatel na implantação dos TACs de conversão de dívida em investimento. Ressalta-se aqui, no entanto, que, com o mecanismo proposto, sempre haverá vitória de um dos dois jogadores. Ou seja, o mecanismo evita a situação existente no mecanismo com limite ao desconto em que há uma probabilidade não trivial de que o projeto não seja executado.

\section{Considerações finais}

O desenvolvimento da presente pesquisa foi motivado pela necessidade de contribuir de forma efetiva com o processo de regulamentação do TAC proposto pela Anatel, bem como com processos semelhantes levados a cabo pelos demais órgãos da administração pública que venham a ter interesse na utilização de mecanismos de solução negociada, através da modelagem de leilão.

Para tanto, foram desenvolvidas duas propostas para a determinação da taxa ótima, do ponto de vista social, de conversão de dívida em projetos de investimento.

A primeira proposta consistiu em modelar cuidadosamente a situação de uma operadora endividada que tem a oportunidade de trocar parte de sua dívida por investimento participando de um leilão em que a estratégia de cada operadora é a taxa de conversão que está disposta a aceitar para celebrar o TAC. Para o agente regulador, a Anatel, quanto mais baixa for a taxa de conversão, menos dívida será abatida pelo mesmo projeto, o que significa que o saldo da dívida poderá ainda ser usado em outros projetos que a instituição teria interesse em fomentar. Portanto, quanto menor for o "lance" da 
operadora, melhor para a Anatel. O jogo bayesiano correspondente foi cuidadosamente construído e seu equilíbrio de Nash computado, mostrando que, quanto maior for o valor presente líquido (VPL) do prejuízo do projeto para a firma, maior será sua exigência de desconto para firmar um TAC com a Anatel. Além disso, quanto maior for a estimativa da probabilidade de que a firma terá realmente que pagar sua dívida, tanto menor será sua exigência de desconto. Finalmente, quanto maior o benefício do projeto para a operadora relativamente ao seu custo, menor será sua exigência de desconto. A análise da primeira proposta mostra ainda que, no equilíbrio de Nash bayesiano, as operadoras exigem uma taxa de conversão maior que aquela que estariam dispostas a aceitar caso a reguladora tivesse informação completa sobre cada operadora. Trata-se da renda informacional que as operadoras recebem devido à sua informação privilegiada (sobre o próprio tipo). A segunda proposta mostra como essa renda informacional pode ser reduzida, aumentando o bem-estar social oriundo dos novos projetos de investimento implantados.

A segunda proposta avalia duas possíveis extensões do modelo original. $\mathrm{Na}$ primeira, considera-se a escolha estratégica de um limite ao desconto a ser aplicado ao vencedor do leilão. Trata-se do equivalente ao preço de reserva em um leilão tradicional. A escolha ótima desse limite tem o potencial de aumentar o bem-estar social associado aos mecanismos de TACs ao custo de permitir a existência de situações em que não há concessionária vitoriosa, ou seja, em que o projeto não será executado.

A segunda extensão se aplica ao ambiente naturalmente sequencial ${ }^{19}$ do problema, uma vez que não se espera que a Anatel celebre um único TAC com cada operadora (exaurindo assim sua dívida), mas que, pelo contrário, a Anatel fomente a implantação de muitos diferentes projetos de alto retorno social. Mas, então, se existir mais de um processo de leilão, o órgão regulador poderá criar uma assimetria entre os jogadores capaz de aumentar o benefício social. Esse princípio é geral e pode ser aplicado inclusive a ambientes outros que os TACs da Anatel. Considerando, por simplicidade, um ambiente de dois leilões consecutivos com dois jogadores, pode-se construir um mecanismo segundo o qual o vencedor do primeiro leilão adquire uma vantagem estratégica sobre o outro jogador no segundo leilão. Essa vantagem, por sua vez, cria uma grande motivação para que ambos os jogadores se esforcem mais para vencer o primeiro leilão (e usufruir a vantagem no segundo leilão), o que faz com que ambos façam lances mais agressivos. 0

\footnotetext{
19 Jofre-Bonet; Persendorfer (2014), Puranam; Katehakis (2012), Leme, Syrgkanis; TARdos (2012), Robu; Poutré (2010).
} 
resultado esperado desse mecanismo que cria assimetria entre os jogadores é uma menor taxa de conversão, considerando os dois leilões, se comparado à aplicação separada e independente de cada um desses leilões.

A extensão detalhada do modelo para a inclusão do mecanismo sequencial de criação de assimetria entre os jogadores é deixada aqui como uma sugestão de pesquisa futura. Ademais, seria interessante explorar como o benefício para o leiloeiro nesse mecanismo sequencial é afetado pelo aumento no número de participantes do leilão. É fato que, em geral, um aumento na participação aumenta a competição entre os participantes, o que aumenta o retorno esperado para o leiloeiro; portanto, esse aumento na participação poderia tornar menos atraente a vitória no primeiro período para os participantes. Por outro lado, a vantagem obtida no segundo período se torna ainda mais relevante quando aumenta o número de participantes, o que poderia tornar a competição ainda mais acirrada no primeiro período. A análise do resultado desse aumento no número de participantes é também deixada aqui como sugestão para estudos futuros ${ }^{20}$.

Mais importantemente para o país, vale notar que, além de sua aplicabilidade no ambiente dos TACs que motivou seu desenvolvimento, os mecanismos aqui estudados podem ser aplicados em muitas outras situações em que existe um relacionamento sequencial entre um principal e vários agentes, sendo que o "preço" envolvido nesse relacionamento não se encontra claramente definido. Portanto, espera-se que o uso de mecanismos de leilão e o princípio da criação de assimetria entre os competidores possam ser amplamente usados no setor público brasileiro.

\section{Referências bibliográficas}

BRASIL. Lei no 7347/1985 (Lei de Ação Civil Pública). Disponível em www.planalto.gov.br/ccivil_03/ leis/17347orig.htm. Acesso em 01/09/2013.

Agência Nacional de Telecomunicações. Resolução no 629 de 16 de dezembro de 2013.

Disponível em www.anatel.gov.br. Acesso em: 15 jan. 2014.

\footnotetext{
${ }^{20}$ Os autores agradecem um parecerista anônimo por chamar a atenção para esse ponto.
} 
Decreto no 2.592/1998. Diário Oficial da União, Brasília, p. 5644, 21 mar. 1997. Disponível em <http://www.planalto.gov.br/ccivil_03/decreto/D2592.htm>. Acesso em: 01 set. 2013.

Exposição de motivos no 231/MC da Lei Geral de Telecomunicações (1996).

Disponível em: http://www.anatel.gov.br/Portal/verificaDocumentos/documento.

asp?numeroPublicacao=331\&assuntoPublicacao=Exposi\%E7\%E3o\%20de\%20Motivos\%20

n.\%BA\%20231\%20/MC\%20de\%2010/12/96,\%20que\%20encaminha\%20a\%20\%20Lei\%20Geral\%20 das\%20Telecomunica\%E7\%F5es.\&caminhoRel=null\&filtro=1\&documentoPath=biblioteca/leis/ exposicao_motivos_lgt.pdf. Acesso em: 03 mai. 2014.

BUgARIN, Maurício. Leilões sequenciais. Trabalho apresentado no Grupo Economia do Setor Público, Departamento de Economia, UnB, em 6/11/2015. Disponível em: https:// bugarinmauricio.files.wordpress.com/2019/10/20151106apresentaccca7acc83o-esp.pdf. Acesso em: 1 ago. 2019.

Jehle, G. A.; RenY, P. J. Advanced Microeconomic Theory. 3. ed. Essex: Prentice Hall, 2011.

JofRe-Bonet,Mireia; Pesendorfer, Martin. Optimal sequential auctions. International Journal of Industrial Organization, v. 33, p. 61-71, 2014.

KATSENOS, Georgios. Three essays on sequential auctions. 2007. Tese de Doutorado. University of Pittsburgh.

KATZMAN, Brett. A two stage sequential auction with multi-unit demands. Journal of Economic Theory, v.86(1), p.77-99, 1999.

KRISHNA, Vijay. Auction theory, 2. ed. Burlington: Academic press, 2010.

LEME, Renato Paes; SYrgkanIS, Vasilis; TARDos, Éva. Sequential auctions and externalities. In: ProceEdings OF THE TWENTY-THIRD ANNUAL ACM-SIAM SYMPOSIUM ON DISCRETE ALGORITHMS. SIAM, 2012. p. 869-886.

MCAFEe, R. Preston; MCMILLAN, John. Bidding rings. The American Economic Review, v. 82(3), p. 579-599, 1992.

Menezes, Flavio M. Auctions of identical objects with single-unit demands: a survey. Revista Brasileira de Econometria, v. 18, n. 2, p. 309-340, 1998.

Menezes, Flavio M.; MonteIRo, Paulo K. An introduction to auction theory. Oxford: Oxford University Press, 2005.

MIRANDA, Rachel de Castro. O sistema judiciário brasileiro: evidências empíricas dos incentivos ao litígio, 2011. Tese de doutorado. Disponível em: https://bibliotecadigital.fgv.br/dspace/bitstream/ handle/10438/8776/Rachel_V\%20Final.pdf. Acesso em 1 jan. 2019.

MYERSON, Roger B. Optimal auction design. Mathematics of operations research, v. 6, n. 1, p. 5873, 1981.

PURANAM, Kartikeya S.; KATEHAKIS, Michael N. On optimal bidding and inventory control in sequential procurement auctions: the multi period case. Annals of Operations Research, v. 217, n. 1, p. 447-462, 2014. 
RoBu, Valentin; LA POUTRÉ, Han. Designing bidding strategies in sequential auctions for risk averse agents. Multiagent and Grid Systems, v. 6, n. 5, p. 437-457, 2010.

Sotomayor, Marilda; BugARIN, Maurício. Lições em Teoria dos Jogos. Mimeo. 2004.

TIROLE, Jean. The theory of industrial organization. Cambridge: MIT press, 1988.

VARIAN, Hal. Microeconomic analysis. 3. ed. New York: W. W. Norton \& Company, 1992.

\section{Maurício Soares Bugarin}

(iD) https://orcid.org/0000-0003-1177-7344

Professor titular do Departamento de Economia da Universidade de Brasília (UnB). PhD in Economics e Master of Science in Economics pela University of Illinois. Mestre e Bacharel em Matemática (1988) pela Universidade de Brasília. Pós-doutor nas universidades de Illinois, Rochester, Tsukuba, Kobe, Yohohama, IDE-Jetro, Vanderbilt. Pesquisador do CNPq e líder fundador do grupo de pesquisa do CNPq "Economics and Politics Research Group".

$\bowtie$ bugarin.mauricio@gmail.com

\section{Hélio Maurício Miranda da Fonseca}

(iD https://orcid.org/0000-0002-0696-1705

Especialista em Regulação da Agência Nacional de Telecomunicações (Anatel). Doutor em Economia pela Universidade de Brasília. Mestre em Engenharia pela Universidade Federal do Rio de Janeiro. Pós-Graduado em Matemática pelo Instituto de Ciências Exatas (IE) da Universidade de Brasília.

$凶$ hmmfonseca@gmail.com 


\section{Apêndice}

\section{Solução do jogo de leilão para precificação do TAC}

Para resolver o problema, foi considerado que, pela simetria do jogo com relação às empresas, o equilíbrio buscado deve ser também simétrico, de forma que as duas empresas escolhem a mesma função estratégia: $d_{1}=d_{2}=d$. Além disso, há a suposição de que, quanto maior for o valor $G_{i}$ do prejuízo, maior será seu desconto pretendido em equilíbrio, ou seja, a função d é estritamente crescente. Por fim, também foi postulado que d é diferenciável.

Como o lance $d$ é estritamente crescente, dado o valor $\delta_{i}$, para $i=1,2$, têm-se que $\operatorname{Pr}\left\{d_{2}\left(G_{2}\right)=\delta_{2}\right\}=\operatorname{Pr}\left\{d_{1}\left(G_{1}\right)=\delta_{1}\right\}=0$.

Sendo a função $d:[0,1] \rightarrow[0,1]$ e focando na solução do problema da empresa 1 , para um dado valor de proposta $\delta_{1}$, a empresa vencerá se propuser um desconto $\delta_{1}<d\left(G_{2}\right)$, em que $d\left(G_{2}\right)$ é o desconto proposto pela empresa 2. Assim, tem-se que:

$$
\delta_{1}<d\left(G_{2}\right) \Leftrightarrow d^{-1}\left(\delta_{1}\right)<G_{2} \Leftrightarrow G_{2}>d^{-1}\left(\delta_{1}\right)
$$

O problema da empresa 1 é, então, maximizar a respectiva utilidade ao propor um desconto $\delta_{1}$, dado $d\left(G_{2}\right)$ e o seu tipo é $G_{1}$ :

$$
\max _{\delta_{1}}\left\{\int_{0}^{d^{-1}\left(\delta_{1}\right)} v_{1} f_{2}\left(G_{2}\right) d G_{2}+\int_{d^{-1}\left(\delta_{1}\right)}^{1} v_{1}^{\prime} f_{2}\left(G_{2}\right) d G_{2}\right\}
$$

Considerando a distribuição uniforme dos tipos, temos: $f_{2}\left(G_{2}\right)=1, \forall G_{2} \in[0,1]$ e o problema se reduz a:

$$
\max _{\delta_{1}} v_{1} d^{-1}\left(\delta_{1}\right)+v_{1}^{\prime}\left(1-d^{-1}\left(\delta_{1}\right)\right)
$$


Mas,

$$
\begin{aligned}
& v_{1} d^{-1}\left(\delta_{1}\right)+v_{1}^{\prime}\left(1-d^{-1}\left(\delta_{1}\right)\right) \\
= & v_{1} d^{-1}\left(\delta_{1}\right)+v_{1}\left(1-d^{-1}\left(\delta_{1}\right)\right)+\left(p_{1} \delta_{1} c-G_{1}\right)\left(1-d^{-1}\left(\delta_{1}\right)\right) \\
= & v_{1}+\left(p_{1} \delta_{1} c-G_{1}\right)\left(1-d^{-1}\left(\delta_{1}\right)\right)
\end{aligned}
$$

Portanto, o problema da empresa 1 se reduz a:

$$
\max _{\delta_{1}}\left\{v_{1}+\left(p_{1} \delta_{1} c-G_{1}\right)\left(1-d^{-1}\left(\delta_{1}\right)\right)\right\}
$$

Se a função acima for côncava, então a condição de primeira ordem (CPO) levará à melhor resposta da firma 1. A CPO é:

$$
\begin{aligned}
& p c\left[1-d^{-1}\left(\delta_{1}\right)\right]+\left(-G_{1}+p \delta_{1} c\right) \times\left(-\left(d^{-1}\right)^{\prime}\left(\delta_{1}\right)\right)=0 \\
& p c-p c d^{-1}\left(\delta_{1}\right)+G_{1}\left(\left(d^{-1}\right)^{\prime}\left(\delta_{1}\right)\right)-p \delta_{1} c\left(\left(d^{-1}\right)^{\prime}\left(\delta_{1}\right)\right)=0
\end{aligned}
$$

Em um equilíbrio de Nash bayesiano, $\delta_{1}$ é escolhido de forma que $\delta_{1}=d\left(G_{1}\right)$. Assim, a equação acima pode ser reescrita como:

$$
p c-p c G_{1}+G_{1}\left(\left(d^{-1}\right)^{\prime}\left(d_{1}\left(G_{1}\right)\right)-p c\left(d_{1}\left(G_{1}\right)\right)\left(\left(d^{-1}\right)^{\prime}\left(d_{1}\left(G_{1}\right)\right)=0\right.\right.
$$

Como $d^{-1}$ é a inversa de $d$, resultando na igualdade $\left(d^{-1}\right)^{\prime}\left(\delta_{1}\right)=\left(d^{\prime}\left(G_{1}\right)\right)^{-1}$, temos que a condição acima se transforma em:

$$
\begin{aligned}
& \frac{G_{1}}{d^{\prime}\left(G_{1}\right)}+p c-p c G_{1}-\frac{p c d\left(G_{1}\right)}{d^{\prime}\left(G_{1}\right)}=0 \\
& G_{1}+d^{\prime}\left(G_{1}\right) p c-d^{\prime}\left(G_{1}\right) p c G_{1}-p c d\left(G_{1}\right)=0 \\
& p c\left[d^{\prime}\left(G_{1}\right)-d^{\prime}\left(G_{1}\right) G_{1}-d\left(G_{1}\right)\right]=-G_{1}
\end{aligned}
$$




$$
\left[d^{\prime}\left(G_{1}\right)\left(1-G_{1}\right)-d\left(G_{1}\right)\right]=-\frac{G_{1}}{p c}
$$

Considerando que $\frac{\partial\left[\left(1-G_{1}\right) d\left(G_{1}\right)\right]}{\partial G_{1}}=\left[d^{\prime}\left(G_{1}\right)\left(1-G_{1}\right)-d\left(G_{1}\right)\right]$, a equação diferencial acima leva à solução abaixo, em que $k$ é uma constante de integração.

$$
\left[\left(1-G_{1}\right) d\left(G_{1}\right)\right]=-\frac{G_{1}{ }^{2}}{2 p c}+k
$$

Fazendo $G_{1}=1$, obtém-se $k$ :

$k=\frac{1}{2 p c}$

Substituindo $k$, obtém-se após algumas operações algébricas:

$$
\begin{aligned}
& {\left[d\left(G_{1}\right)\right]=\left[-\frac{G_{1}{ }^{2}}{2 p c}+\frac{1}{2 p c}\right] \times \frac{1}{\left(1-G_{1}\right)}=\frac{\left(1+G_{1}\right)\left(1-G_{1}\right)}{2 p c} \times \frac{1}{\left(1-G_{1}\right)}} \\
& d\left(G_{1}\right)=\frac{G_{1}+1}{2 p c}
\end{aligned}
$$

Considerando a simetria, o lance do jogador 2 em equilíbrio é:

$$
d\left(G_{2}\right)=\frac{G_{2}+1}{2 p c}
$$

Resta verificar que $d_{1}(G)=d_{2}(G)=\frac{G+1}{2 p c}$ corresponde, de fato, a um equilíbrio de Nash Bayesiano (ENB) do jogo, ou seja, que a função objetivo do jogador 1 é, de fato, côncava quando o jogador 2 segue a estratégia $d_{2}(G)=\frac{G+1}{2 p c}$. Para tanto, note primeiramente que $d_{2}(G)=\frac{G+1}{2 p c} \Leftrightarrow d_{2}^{-1}\left(\delta_{1}\right)=$.

Substituindo na função-objetivo do jogador 1, temos:

$$
\max _{\delta_{1}}\left\{v_{1}+\left(p_{1} \delta_{1} c-G_{1}\right)\left(1-\left(2 p c \delta_{1}-1\right)\right)\right\}=\left\{v_{1}+2\left(p_{1} \delta_{1} c-G_{1}\right)\left(1-p c \delta_{1}\right)\right\}
$$


Note que a função objetivo é um polinômio de grau dois, uma parábola volta para baixo em $\delta_{1}$. Portanto, trata-se realmente de uma função estritamente côncava e a abordagem baseada na condição de primeira ordem está adequada.

\section{Solução do jogo de leilão para precificação do TAC com limite máximo ao desconto}

Vimos que, se a operadora $i$ for do tipo $G_{i}>p c \Delta$, então preferirá não fazer lance algum, não tendo interesse em vencer o leilão. Portanto, somente terá interesse em participar do leilão a operadora para a qual $G_{i} \leq p c \Delta$. Nesse caso a operadora resolve o mesmo problema de otimização que no caso em que não há restrição ao desconto, chegando novamente à condição abaixo, em que $k$ é um parâmetro a ser determinado.

$$
\left[\left(1-G_{1}\right) d\left(G_{1}\right)\right]=-\frac{G_{1}{ }^{2}}{2 p c}+k
$$

A novidade agora diz respeito à condição de contorno, que passa a ser a seguinte: $G_{i}=p c \Delta$, então $d_{i}\left(G_{i}\right)=\Delta$. Substituindo na equação acima, obtemos:

$$
[(1-p c \Delta) \Delta]=-\frac{p c}{2} \Delta^{2}+k \text { donde } k=\Delta-\frac{p c}{2} \Delta^{2}
$$

Mas então substituindo na expressão acima obtemos:

$$
\left[\left(1-G_{1}\right) d\left(G_{1}\right)\right]=-\frac{G_{1}{ }^{2}}{2 p c}+\Delta-\frac{p c}{2} \Delta^{2}
$$

Donde chega-se à expressão:

$$
d_{i}\left(G_{i}\right)=\frac{1+G_{i}}{2 p c}-\frac{(1-p c \Delta)^{2}}{2 p c} \frac{1}{1-G_{i}}, G_{i} \in[0, p c \Delta], i=1,2 .
$$

